\title{
ANALISIS FAKTOR-FAKTOR YANG MEMPENGARUHI KEPATUHAN WAJIB PAJAK (Studi Kasus Pada KPP Pratama Sukabumi)
}

\section{ANALYZE THE FACTORS THAT AFFECT TO TAXPAYER COMPLIANCE (Case Study on KPP Pratama Sukabumi)}

\author{
L.Susanti, M.M.Melani \\ Jurusan Akuntansi Fakultas Ekonomi Universitas Djuanda Bogor \\ Email : Lusi.susanti@unida.ac.id,mariamagdalenamelani2@gmail.com
}

\begin{abstract}
Taxpayer compliance in paying taxes is a strategic position in terms of increasing tax revenues, but in reality there are still taxpayers who deliberately commit fraud causing tax arrears. Simple random sampling technique was used to obtain the sample and slovin equation was further used in order to get 100 respondents in this research. The data were collected by survey through questioner. Data analysis and verification were done by double linier regression analysis using SPSS program of windows version 20 . All the instrumen in this research are valid and reliable. Furthermore, the model used in this research is also appropriate to explain the variables of tax compliance. The final analysis and hypothesis verification showed thet the taxpayer awareness, tax penalty, and tax authority's service have a positive impact and a significant role on improving the taxpayer compliance either simultaneously or partially. The contribution of taxpayer awareness, tax penalty, and outhority's service in this research is 61 percent.
\end{abstract}

Keywords : taxpayer awareness, tax penalty, authority’s service, taxpayer compliance.

\begin{abstract}
ABSTRAK
Kepatuhan wajib pajak dalam membayar pajak merupakan posisi strategis dalam hal peningkatan penerimaan pajak, akan tetapi pada kenyataannya masih terdapat wajib pajak yang sengaja melakukan kecurngan sehingga menyebaabkan timbulnya tunggakan pajak. Teknik pengambilan sampel menggunakan simple random sampling, dengan menggunakan rumus slovin sehingga didapat 100 responden dalam penelitian. Pengumpulan data menggunakan teknik survey dengan melakukan penyebaran kuesioner. Pengujian dan analisis data menggunakan analisis regresi linier berganda dengan menggunakan program SPSS versi 20 for windows. Semua intrumen dalam penelitian ini valid dan reliabel, serta model yang digunakan layak untuk menjelaskan varibel kepatuhan wajib pajak. Hasil analisis dan pengujian hipotesis yang dilakukan menunjukan bahwa kesadaran wajib pajak, sanksi pajak dan pelayaanan fiskus berpengaruh positif dan signifikan terhadap kepatuhan wajib pajak baik secara simultan maupun parsial. Besarnya kontribusi dalam penelitian ini sebesar 61 persen.
\end{abstract}

Kata kunci : Kesadaran Wajib Pajak, Sanksi Pajak, Pelayanan Fiskus, Kepatuhan Wajib Pajak 


\section{PENDAHULUAN}

sumber penerimaaan utama negara salah satunya berasal dari pajak, penerimaan ini mempunyai umur tidak terbatas, terlebih degan semakin bertambahnya jumlah penduduk yang mengalami peningkatan setiap tahunnya. Pajak memiliiki peran yang sangat besar dan semakin diandalkan untuk kepentingan pembangunan dan pengeluaran pemerintah. Usaha untuk maksimalkan penerimaan pajak tidak hanya mengandalkan peran wajib pajak. Perubahan official assessment menjadi self assessment, memberikan kepercayaan wajib pajak untuk mendaftar, menghitung, dll (Arum, 2012). Salah satu diberlakukan reformasi sistem self assessment adalah untuk meningkatkan kepatuhan membayar pajak.

Kepatuhan wajib pajk secara sukarela merupakan tulang punggung dari self assessment system. Salah satu kendaala yang dapat menghambaat kefektifan pengumpulan pajak adalah kepatuhann wajib pajak. Kepatuhan WP dipengaruhi oleh beberapa faktor salah satu adalah kesadaran wajib pajak. Ritongga (2011) kesadaran merupakan perilaku/sikap terhadap objek yang melibatkan perasaan serta kecenderungan untuk bertindak sesuai objek tersebut. Kesadaran wajib pajak dalam membayar pajak merupakan perilaku wajib pajak berupa pandangaan/ perasaan yang melibatkan pengetahuan, keyyakinan disertai kecenderungan untuk bertindak sesuai peraturan yang diterbitkan oleh sistem ketentuan pajak.

Kepatuhan WP dapat ditingkatkan melalui pengenaan sanksi pajak. UU telah mengatur bagaimana pelaksanaan ketentuan umum dan tata cara perpajakan, termasuk sanksi yang akan dikenakan apabila wajib pajak tidak memenuhi kewajiban perpajakan.
Dikenakannya sanksi bertujuan untuk mencegah ketidakpatuhan wajib pajak. ketegasan DJP dalam menerapkan sanksi pajak pada wajib pajak yang tidak memenuhi kewajibannya perpajakanya sangat diperlukan agar terbentuk perilaku kepatuhan wajib pajak.

Kepatuhan wajib pajk dalam memenuhi kewajibann perpajakan tergantung bagaimana sikap petugas pajaknya memberikan pelayanan yang terbaik kepada wajib pajak. Pelayanan fiskus yang baik diharapkan mampu meningkatkan kepatuhan WP, seperti diatur melalui surat edaran DJP nomor SE-84/PJ/2011 tentang pelayanan prima. Dalam penelitian Supadmi (2010) disebutka bahwa untuk meningkaatkan kepatuhan WP dalam memenuhi kewajiban perpajakannya, kwalitas pelayanan pajak harus ditingkatkan oleh aparat pajak, pelayanan fiskuss yang baik akan memberikan kenyamaanan bagi wajib pajak.

Kepatuhan wajb pajak dalam membayar pajak merupakan posisi strategis dalam hal peningkatan penerimaan pajak, akan tetapi dalam kenyataannya masih terdapat wajib pajak yang dengan segaja melakukan kecurangan dan melalaikan kewajiban perpajakannya, sehingga menyebakan timbulnya tunggakan pajak berikut disajikan tentang tingkat kepatuhan waib pajaak di KPP Pratama Sukabumi dari tahun 2013 hingga 2016 tabel 1:

Tingkat kepatuhan WP 2013-2016

\begin{tabular}{ccccc}
\hline No. & Tahun & $\begin{array}{c}\text { Jumlah } \\
\text { WP }\end{array}$ & $\begin{array}{c}\text { Jumlah } \\
\text { SPT }\end{array}$ & $\begin{array}{c}\text { Kepatu } \\
\text { han \% }\end{array}$ \\
\hline 1 & 2013 & 115,977 & 43,018 & $37,09 \%$ \\
2 & 2014 & 126,909 & 50,032 & $39,42 \%$ \\
3 & 2015 & 129,868 & 59,941 & $46,16 \%$ \\
4 & 2016 & 161,115 & 100,637 & $62,46 \%$ \\
\hline
\end{tabular}

Sumber: KPP Pratama Sukabumi, 2017 
Berdasarkan tabel diatass menunjukan bahwa WP yang terdaftar dari tahun ketahun terus meningkat, namun tingkat kepatuhan WP masih tergolong rendah hanya berkisar dibawah $77 \%$ kriteria yang telah ditetapkan dalam surat edaran DJP nomor 06/PJ/2017 tentang strategi peningkatan kepatuhan WP dan penetapan target rasioo kepatuhan WP.

\section{Tinjauan Pustaka dan Pengembangan Hipotesis \\ Kesadaran Wajib Pajak}

Kesadaran merupakan unsur dalam diri manusia untuk memahami dan bersikap terhadap realitas. Nurmantu (2005) kesadaran waib pajk merupakan penilaian posiitif masyarakat wajib pajak trhadap pelaksanaaan fugsi negara oleh pemerintah akan menggeerakan masyaraakat mematuhi kewajibannya untuk membayar pajak.

\section{Sanksi Pajak}

Sanksi dalam kegiatan perpajakan sangatlah diperlukan untk memberikan efek jera bagi paraa pelanggarnya dan meninggkatkan kepatuhan waajib pajak dalam melaksanakan kewajibannya untuk membayar pajak. Mardiasmo (2011) sanksi pajak adalah jaminan untuk ketenntuan peraturan UU perpajakan akan dituruti/ditaati, atau bisa dengan sanksi perpajaakan mrupakan alat pencegah agar wajb paak tidak melanggar norrma perpajakan.

\section{Pelayanan Fiskus}

Kepatuhan wajjib pjak untuk memenuhi kewajiban memabayar paajak tergantung paada sikap fiskus dalam memberikan pelayanan terbaik pada wajib pajak. Jatmiko (2006) pelayanan adalah cara melayani, membantu mengurus/menyiapkan sgala keperluan yg dibutuhkan seseorang. Fiskus adalah petugas pajak, jadi pelayanan fiskus adalah cara petugas pajak dalam membantu mengurus/menyiapkan sgala keperluan yang dibutuhkan seeseorang (wajib pajak).

\section{Kepatuhan Wajib Pajak}

Kepatuhan pajak merupakan tindakan patuh seseorang, yang dimaksud disini adalah wajiib pajak terhdap peraturan undang-undang perpajakan. Tiraada (2013) pemenuhaan kewajiban perpajakan yang dilakukan oleh pembaar pajak dalam rangka memberikan kontrbusi bagi pembangunan negara yang diharapkan di dalam pemenuhanya dilakukan secara sukarela.

\section{Pengembangan Hipotesis \\ Pengaruh Kesadaran Wajib Pajak terhadap Kepatuhan Wajib Pajak}

Kesadaran membayar pajak merupakan unsur dalam manusia untuk mmahami realitas dan cara bertindak/menyikapi untuk patuh membayar pajak kepada kas negara untuk kepentingan bersama. Kesadaran yg dimiliki oleh manusia meliputi kesdaran dalam diri dan kemungkinan masa depannya. Rendahnya kesadaran perpajakan masyarakat seringkli menjadi kendala dlam masalah pengumpulan pajaak dari masyarakat. Hal ini dapatt dikarenakan ketidaktahuan mereka tentang wujud konkrit imbalan dari uang yang dikeluakan untk membayar pajak.

Hipotesis pertama sebagai berikut:

H1 : Diduga kesadaran wajib pajak berpengaruh positif dan signifikan terhadap kepatuhan wajib pajak

\section{Pengaruh Sanksi Pajak Terhadap Kepatuhan Wajib Pajak}

Ketenttuan umum dan tata cara perpajakann telah diatur dalam UndangUndang. Supaya peraturan pajak dipatuhi, maka harus ada sanksi pajak yang tegas bagii pelanggyarn. WP akan memenuhi kewajiban pajak bila 
memandang sanksi pajak akan lebih banyak merugikan. lebih banyak merugikannya. Semakin bnyak sisa tunggakan pajak, maka akan semakin berat wajib pajak untuk mlunasinya. Pandangan WP mengenai sanksi perpajakan diduga akan mempengaruhi kpatuhan waajib pajak dlam membayar pajak. Dengan demikian, sanksi paajak adalah jaminn bahwa ketentuan peraturan udang-undang perpajakan akan diturutti, ditaati atau dipatuhi, sanksi perpajaakn merupakan alat pencegah supaya WP tidak melanggar norma perpajakan.

Hipotesis yang kedua sebagai berikut:

H2 : Diduga sanksi pajak berpengaruh positif dan signifikan terhadap kepatuhan wajib pajak

\section{Pengaruh Pelayanan Fiskus Terhadap Kepatuhan Wajib Pajak}

Kpatuhan WP dalam memenuhi kewajibann memabayar pajak tergantung pada bagaimana sakap petugas pajak (fiskus) mmberikan suatu pelayanan terbaik kepada wajib pajak. pelayanann yang diberikan oleh fiskus selama proses pajak yang berkaitan dengan sikap wajib pajak. Proses perpajkan melibatkan fiskus dan wajib pajak membuat pelayaann yang diberikan fiskus turut membentuk sikap WP dalam proses perpajakan. Semakin baik pelayanan fiskus, maka semakin tinggi tingkat kepatuhan WP dalam membayar pajak.

Hipotesis yang ketiga sebagai berikut:

H3 :Diduga pelayanan fiskus berpengaruh positif dan signifikan terhadap kepatuhan wajib pajak

\section{METODE PENELITIAN}

Penelitian ini dilakukan di lingkunagn Kantor Pelayanan Pajak Pratama Sukabumi yang beralamat di Jalan R.E Martadinata No. 1 Sukabumi.

Penlitian ini merupakan penelitian deskriptif, dengan teknik explanatory. Peneltian ini mengambil sampel dari populasi dan menggunakan kuesioner sebagai alat pengumpulan data utama. Data sekunder didapat dengan menelaah data yang diperoleh di KPP Pratama Sukabumi yang diterbitkan.

Variabel Penelitian dan Definisi Operasional Variabel

Penelitin ini terdiri dari dua variabel, yaitu variabel bebas terdiri dari Kesadaran Wajib Pajak (X1), Sanksi Pajak (X2), dan Pelayanan Fiskus (X3). Sedangkan variabel terikat yaitu Kepatuhan Wajib Pajak (Y) pada KPP Pratama Sukabumi.

\section{Populasi dan Sampel Penelitian}

Populasi dalam penelitian ini adalah Wajib Pajak (Badan dan Orang Pribadi) yang terdaftar di KPP Pratama Sukabumi.

Penentuan pengambilan sampel ditentukan dengan menggunakan teknik probability sampling dan lebih spesifiknya penulis menggunakan simple random sampling. Rums yang digunakan untuk menentukan sampel yaitu menggunakan rumus slovin:

$$
\mathrm{n}=\frac{\mathrm{N}}{\left(\mathrm{N} \cdot \mathrm{e}^{2}\right)+1}
$$

Dimana:

$\mathrm{n}=$ Jumlah Sampel

$\mathrm{N}=$ Populasi

$\mathrm{e}=$ Presentase kelonggaran penelitian ini $10 \%$.

Berdasarkan data dari KPP Pratama Sukabumi hingga tahun 2016 tercatat sebanyak 161,115 jumlah wajib pajak, maka jumlah sampel menggunakan rumus slovin didapat 99,9 dibulatkan menjadi 100 responden.

\section{Pengujian Data}

Pengumpulan data primer dilakukan dengan metode survey menggunakan media angket (kuesioner), sjumlah pertanyaan diajukan kepada responden 
dan kemudian respodeen dimintaa menjawab sesuai pendapat responden dengan menggunakan skala likert. Bobot nilai yang digunakan dalam setiap pertanyaan dibawah ini:

Tabel 2 Penilaian Kuesioner

\begin{tabular}{c|c}
\hline Bobot Nilai & Jawaban Responden \\
\hline 1 & Sangat Tidak Setuju \\
2 & Tidak Setuju \\
3 & Kurang Setuju \\
4 & Setuju \\
5 & Sangat Setuju \\
\hline
\end{tabular}

Sumber : Sugiyono, 2013

Sedangkan tabel dibawah merupakan kriteria penilaian

\begin{tabular}{c|c}
\hline Skala & Interprestasi \\
\hline $1,00-1,80$ & Sangat Tidak Baik \\
$1,81-2,60$ & Tidak Baik \\
$2,61-3,40$ & Cukup \\
$3,41-4,20$ & Baik \\
$4,21-5,00$ & Sangat Baik \\
\hline
\end{tabular}

Sumber : Sugiyono, 2014

\section{Uji Validitas}

Sebelum menggunakan kuesioner untuk pengumpulan data terlebih dahulu diuji validitas pada responden dengan menggunakan rumus teknik korelasi product momnt (Sugiyono, 2007):

$$
\mathrm{r}=\frac{N\left(\sum x y\right)-\left(\sum x \sum y\right)}{\sqrt{\left.\left(N \sum x^{2}\right)-\left(N \sum x\right)^{2}\left(N \sum y^{2}\right)-\left(\sum y\right)^{2}\right)}}
$$

Dimana:

$\mathrm{r}=$ Koefesien validitas item yang dicari

$\mathrm{x} \quad$ = Skor yang diperoleh dari subjek dalam tiap item

$\mathrm{y}=$ Skor total yang diproleh dari subyek seluruh item.

$\sum \mathrm{x}=$ Jumlah skor distribusi $\mathrm{x}$

$\sum \mathrm{x}^{2}=$ Jumlah kuadrat masing-masing $\mathrm{x}$

$\sum \mathrm{y} 2=$ Jumlah kuadrat pada masingmasing y

$\mathrm{N}$ = Jumlah responden. Tabel 4 Kriteria Uji Validitas

\begin{tabular}{c|c}
\hline $\begin{array}{c}\text { Corrected Item Total } \\
\text { Correlation }\end{array}$ & Keterangan \\
\hline$\geq 0,3$ & Valid
\end{tabular}

\begin{tabular}{c|c}
$<0,3$ & Tidak Valid \\
\hline Sumber : Sugiyono, 2007 &
\end{tabular}

\section{Uji Reliabilitas}

Untuk uji reliabilitas menggunakan teknk cronbach (Ghozli, 2011). Rumus teknik cronbach sebagai berikut:

$$
\mathrm{r} 11=\left[\frac{\mathrm{K}}{\mathrm{K}-1}\right]\left[\frac{\sum \sigma_{\mathrm{b}}^{2}}{1-\sigma_{\mathrm{t}}^{2}}\right]
$$

Dimana:

r11 = Reliabilias instrumen

$\mathrm{K}$ = Banyak butir pertanyaan

$\sigma_{t}^{2} \quad=$ Varian total

$\sum \sigma_{b}^{2}=$ Jumlah varians butir

Tabel 5 Kriteria Uji Reliabilitas

\begin{tabular}{c|c}
\hline Alpha Cronbach & Keterangan \\
\hline$>0,6$ & Reliabel \\
$<0,6$ & Tidak Reliabel \\
\hline
\end{tabular}

Sumber : Sugiyono, 2007

Uji Asumsi Klasik

Sebelum melakukan pengujian hipotesis, maka terlebih dahulu dilakukan uji asumsi klasik yang mendasari dan menjadi persyaratan statistik yang harus dipenuhi dalam penggunaan analis regresi dan koefesien regresi yang linier, tidak bias, konsisten, serta efisien. Asumsi klasik menurut Ghozali (2011) adalah uji normalitas, uji multikolonieritas dan uji hateroskedastistas.

\section{Metode Pengolahan dan Analisis Data}

Regresi linear berganda

(Nugroho, 2011), sbagai berikut:

$$
Y=a+\beta_{1} X_{1}+\beta_{2} X_{2}+\beta_{3} X_{3}+\varepsilon
$$

Dimana:

Y =kepatuhan wajib pajak.

$\mathrm{A} \quad=$ nilai konstanta.

$\mathrm{X}_{1} \quad=$ kesadaran WP terhadap kepatuhan WP.

$\mathrm{X}_{2} \quad=$ sanksi pajak terhadap kepatuhaan wajib pajak

$\mathrm{X}_{3}=$ pelyanan fiskus terhadap keaptuhan wajib pajak.

$\varepsilon \quad=$ faktor lain yang diteliti

$\beta_{1}=$ koefisien regresi variabel $\mathrm{x}_{1}$ 
$\beta_{2}=$ koefisien regresi variabel $\mathrm{x}_{2}$

$\beta_{3}=$ koefisien regresi variabel $\mathrm{x}_{3}$

koefesien korelasi berganda alat ini digunakan untk mengukur tingkat hubungan antara variabel-variabel bebas $(\mathrm{X})$ terhadap variabel terikat $(\mathrm{Y})$.

Tabel 6 Pedoman untuk interprestasi koefisien korelasi

\begin{tabular}{c|c}
\hline Interval Nilai $\mathbf{r}$ & Interprestasi \\
\hline $0,001-0,200$ & Sangat Lemah \\
$0,201-0,400$ & Lemah \\
$0,401-0,600$ & Cukup Kuat \\
$0,601-0,800$ & Kuat \\
$0,801-1,000$ & Sangat Kuat \\
\hline
\end{tabular}

Sumber : Sugiyono, 2007

Koefiein determinasi (Ghozli, 2011), Rumusnya sebagai yaitu:

$$
\mathrm{KD}=\mathrm{r}^{2} \times 100 \%
$$

Dimana :

$\begin{array}{ll}\mathrm{KD} & =\text { koefesien determinasi. } \\ \mathrm{r} & =\text { koefesien korelasi. }\end{array}$

\section{Uji Hipotesis}

\section{Uji Simultan (f-test)}

Langkah-langkah pengujian dengan menggnakan uji F sebagai berikut:

a. Perumusan hipotesis

Ho: $\beta_{1}, \beta_{2}, \beta_{3}=0$; kesadaran $\mathrm{WP}$, sanksi pajak dan pelayanan fiskus tidak terdapat pengaruh seacara simltan terhadap kepatuhan WP.

Ha: $\beta_{1}, \beta_{2}, \beta_{3} \neq 0$; kesadaran wajb pajak, sanksi pajak dan pelayanan fiskus terdapat pengaruh secara simultan trhadap kepatuhan wajib pajk.

b. Menentukan tingkat signifikasi dengan menggunakan tingkat signifikasi $0,05(a=5 \%)$, dengan kriteria keputusan yaitu apabila signifikan < 0,05 maka Ho ditolak, Ha diterima dan apabila signifikan $>0,05$ maka $\mathrm{H}_{\mathrm{o}}$ diterima $\mathrm{H}_{\mathrm{a}}$ ditolak.

c. Kriteria keputusan uji $\mathrm{F}$

1) Jika $F_{\text {hitung }}>F_{\text {tabel }}$ dengan $a=0,05$ maka $\mathrm{H}_{0}$ ditolak dan $\mathrm{H}_{\mathrm{a}}$ diterima.

2) Jika $F_{\text {hitung }}<F_{\text {tabel }}$ dengan $a=0,05$ maka $\mathrm{H}_{\mathrm{o}}$ diterima dan $\mathrm{H}_{\mathrm{a}}$ ditolak.

\section{Uji Parsial (t-test)}

Langkah-langkah uji $\mathrm{t}$ adalah sebagai berikut:

a. Menyusun hipotesis observasi $\left(\mathrm{H}_{\mathrm{o}}\right)$ dan hipotesis alternatif $\left(\mathrm{H}_{\mathrm{a}}\right)$

$\mathrm{H}_{\mathrm{o}}: \beta_{1}=0$; kesadaran wajb pajak tidak terdapat pengaruh terhadap kepatuhan wajib pajak.

$\mathrm{H}_{\mathrm{a}}: \beta_{1} \neq 0$; kesadaran wajib pajk terdapat pengarh terhadap kepathan wajb pajak.

$\mathrm{H}_{\mathrm{o}}: \beta_{2}=0$; sanksi pajak tidak terdapat pengaruh terhadap kepatuhn wajib pajk.

$\mathrm{H}_{\mathrm{a}}: \beta_{2} \neq 0$; sanksi pajak terdapat pengaruh terhadp kepatuhan wajib pajak.

Ho: $\beta 3=0$; pelayanan fiskus tidak terdapat pengaruh terhadap kepatuhan wajb pajak

Ha: $\beta 4 \neq 0$; pelayanan fiskus terdapat pengaruh terhadap kepatuhan wajib pajak.

b. Menentukan tingkat signifikansi menggunakan tingkat signifikansi $0,05(a=5 \%)$, dengan kriteria keputusan yaitu apabila signifikan < 0,05 maka $\mathrm{H}_{\mathrm{o}}$ ditolak $\mathrm{H}_{\mathrm{a}}$ diterima dan apabila signifikan > 0,05 maka $\mathrm{H}_{\mathrm{o}}$ diterima $\mathrm{H}_{\mathrm{a}}$ ditolak.

c. Kriteria uji t adalah:

1) Jika $t_{\text {hitung }} \leq t_{\text {tbel }}$, maka $H_{o}$ diteriima dan $\mathrm{H}_{\mathrm{a}}$ ditolak.

2) Jika thitung $>t_{\text {tabl }}$, maka $\mathrm{H}_{\mathrm{o}}$ ditolak dan $\mathrm{H}_{\mathrm{a}}$ diterima.

Adapun bentuk pengujian hipotesis yng digunakan yaitu uji dua pihak dapat dilihat pada gambar 1 :

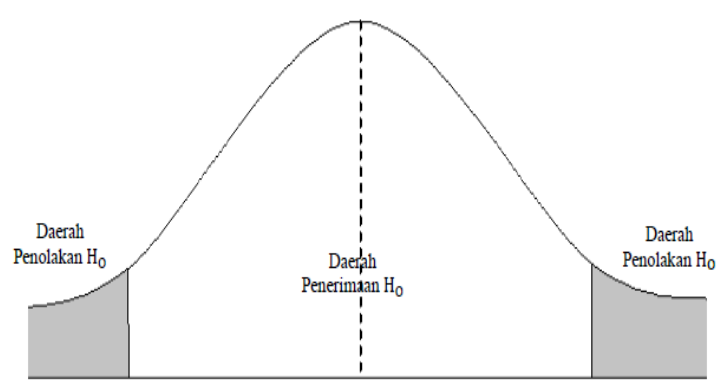




\section{HASIL DAN PEMBAHASAN}

Kantor Pelayanan Pajak (KPP) Pratama Sukabumi adalah salah satu instansi vertical DJP yang mempunyai tugas melaksanakaan penyuluhan, pelayanan, dan pengawasan wajib pajak dibidang pajak penghasilan, pajak pertambahan nilai, pajak penjualan ats barang mewaah, pajak tidak langsung lainnnya, pajak bumi dan bngunan serta bea peroleehan hak atas tanah dan bangunan dalam wilaah weewenangnya berdasarkan UU yang berlaku. KPP Pratama Sukabumi mulai beroperasi sejak 28 Agustus 2007 (sesuai dengan keputusan direktur jendral pajak nomor KEP-112/PJ/2007 tanggal 9 agustus 2007) yang diresmikan oleh menteri keuangan pada tanggal 3 september 2007 di bandung se Kantor Wilayah DJP Jawa Barat I.

KPP Pratama Sukabumi memiliki wilayah kerja dengan dua daerah tinggat II, yaitu kota sukabumi dengan luas wilayah $52,46 \mathrm{~km} 2$ terdiri dari 7 kecamatan dan 33 kelurahann dengan jumlah penduduk sebanyak 308,508 jiwa dan kabupaten sukabumi dengan luas wilayah 4,162 km2 terdiri dari 42 kecamatan, 5 kelurahan dan 381 desa dengan total jumlah penduduk sebanyak 2,408,338 jiwa.

Berdasarkan jenis kelamin menunjukan bahwa tingkat proporsi responden menurut jenis kelamin yang tersebar dalm penelitiian ini adalah lakilaki dengan jumlah responden sebanyak 79 orang, dan responden perempuannya sebanyak 21 orang dapat dikatakan bahwa sebagian besar respoden laki-laki cenderung lebih aktif dan rajin dalam hal melaksanakan perpajakannya dibandingkan perempuan.

Berdasarkan jenis wajib pajak data yang dipilih melalui kuesioner yang diisi oleh respnden menunjukan bahwa responden wajiib pajak badan sebesar 62 responden, sedangkan responden
WPOP yang mellakukan kegiatan usaha sebesar 38 responden. Dari presentase tersebut mayoritas respnden dalam penelitian ini adalah wajib pajak badan, dikarenakan WP badan yang diwajibkan menyelenggarakan pembuukuan tanpa terkecuali jika dibandingkan dengan WPOP yang melakukan kegiatan usaha yang masih minim menyelnggarakan pemubukuan.

Berdasarkan usia responden wajib pajak yang berusiia dibawah 25 tahun sebanyak 5 reponden, usia 26-30 tahun sebanyak 10 responden, usia 3135 sebanyak 21 responden, usia 36-40 sebanyak 52 responden, dan $>40$ tahun sebanyak 12 responden. Dapat disimpulkan bahw mayoritas responden berusia 36-40 tahun, hal ini disebabkan pengalaman hidp yang matang membuat mereka lbih paham dalam mengembangkan usaha yang dijalankannya.

Bersadarkan pendidikan terakhir responden WP pada penelitian ini dengan pendidikan terakhir SMA sebanyaj 20 responden, D3 sebanyak 25 responde, S1 sebanyak 45 responden, dan S2 sebanyak 10 responden. Dapat diisimpulkan bahawa mayoritas responden berpendidikan $\mathrm{S} 1$, hal ini disebabkan dengan adanya tingkat pengetahuan yang tinggi membuat wajib pajak mampu bersaing dan berani mengembangkan kemampuan mereka dengan mengandalkan pengetahuan yang mereka milikii dibanding pelaku WP yang berpendidikan lebih rendah dari S1.

Berdasarkan hasil jawaban mengenai karakteristik wajib pajak, dapat dilihat rekapitulasi dari keseluruhan kriteria respnden wajib pajk pada KPP Pratama Sukabumi pada tabel 7: 
Rekapitulasi Karakteristik Responden

\begin{tabular}{cccc}
\hline No & $\begin{array}{c}\text { Kriteria } \\
\text { Responden }\end{array}$ & Karakteristik & $\begin{array}{c}\text { Jumlah/o } \\
\text { rang }\end{array}$ \\
\hline 1 & Jenis & Laki-laki & $79(79 \%)$ \\
& Kelamin & & \\
2 & Jenis Wajib & Badan & $62(62 \%)$ \\
& Pajak & & \\
3 & Usia & $36-40$ & $52(52 \%)$ \\
4 & Pendidikan & S1 & $45(45 \%)$ \\
\hline
\end{tabular}

Sumber : Data diolah, 2017

\section{Kesadaran Wajib Pajak}

Rekapitulasi skor tanggapan mengenai kesadaran WP terhadap kepatuhan wajiib pajak pada KPP Pratama Sukabumi dapat dilihat pada tabel 8:

Rekapitulasi Skor Tanggapan Wajib Pajak terhadap Kepatuhan Wajib Pajak

\begin{tabular}{|c|c|c|c|}
\hline No & $\begin{array}{c}\text { Pertanyaan/Pernyata } \\
\text { an }\end{array}$ & $\begin{array}{c}\text { Jawab } \\
\text { an }\end{array}$ & $\begin{array}{c}\text { Keteran } \\
\text { gan }\end{array}$ \\
\hline 1 & $\begin{array}{lr}\text { pajak } & \text { merupakan } \\
\text { bentuk } & \text { partisipasi } \\
\text { dalam } & \text { menunjang } \\
\text { pembangunan negara }\end{array}$ & 4,46 & $\begin{array}{l}\text { Sangat } \\
\text { Setuju }\end{array}$ \\
\hline 2 & $\begin{array}{l}\text { pajak meruupakan } \\
\text { sumber penerimaan } \\
\text { negara yang terbesar }\end{array}$ & 4,48 & $\begin{array}{l}\text { Sangat } \\
\text { Setuju }\end{array}$ \\
\hline 3 & $\begin{array}{l}\text { pajak harus dibayar } \\
\text { karena pajak } \\
\text { merupakan kewajiban } \\
\text { warga negara }\end{array}$ & 4,43 & $\begin{array}{l}\text { Sangat } \\
\text { Setuju }\end{array}$ \\
\hline 4 & $\begin{array}{l}\text { pajak ditetapkan } \\
\text { dengan Undang-Udang } \\
\text { dan dapat dipaksakan }\end{array}$ & 4,46 & $\begin{array}{l}\text { Sangat } \\
\text { Setuju }\end{array}$ \\
\hline \multirow[t]{3}{*}{5} & $\begin{array}{l}\text { iuran rakyat untuk } \\
\text { membiayai } \\
\text { pembangunan sarana } \\
\text { publik }\end{array}$ & 4,48 & $\begin{array}{l}\text { Sangat } \\
\text { Setuju }\end{array}$ \\
\hline & Total & 22,31 & \\
\hline & Nilai Rata-rata & 4.46 & $\begin{array}{l}\text { Sangat } \\
\text { Setuju }\end{array}$ \\
\hline
\end{tabular}

Sumber: Data Diolah, 2017

\section{Sanksi Pajak}

Rekapitulasi skor tanggapan mengenai sanksi pajak terahadap kepaatuhan wajib pajak pada KPP Pratama Sukabumi dapat dilihat pada tabel 9:

Rekapitulasi Skor Tanggapan Variabel Sanksi Pajak

\begin{tabular}{ccccc}
\hline No & $\begin{array}{l}\text { Pertanyaan/Pernyat } \\
\text { aan }\end{array}$ & $\begin{array}{c}\text { Jawab } \\
\text { an }\end{array}$ & $\begin{array}{c}\text { Keteran } \\
\text { gan }\end{array}$ \\
\hline 1 & $\begin{array}{l}\text { Petugas pajak telah } \\
\text { memberikan }\end{array}$ & 4,67 & $\begin{array}{l}\text { Sangat } \\
\text { Setuju }\end{array}$
\end{tabular}

\begin{tabular}{|c|c|c|c|}
\hline & $\begin{array}{ll}\text { pelayanan } & \text { pajak } \\
\text { dengan baik } & \end{array}$ & & \\
\hline 2 & $\begin{array}{l}\text { Petugas pajak } \\
\text { senantiasa } \\
\text { memperhatikan }\end{array}$ & 4,42 & $\begin{array}{l}\text { Sangat } \\
\text { Setuju }\end{array}$ \\
\hline & keberatan Wajib & & \\
\hline & $\begin{array}{l}\text { Pajak atas pajak yang } \\
\text { dikenakan }\end{array}$ & & \\
\hline 3 & $\begin{array}{l}\text { Sanksi pajak yang } \\
\text { dikenakan bagi } \\
\text { pelanggar aturan } \\
\text { pajak ckup berat }\end{array}$ & 4,46 & $\begin{array}{l}\text { Sangat } \\
\text { Setuju }\end{array}$ \\
\hline 4 & $\begin{array}{lr}\text { Sanksi pajak } & \text { harus } \\
\text { dikenakan } & \text { kepada } \\
\text { pelanggarnya } & \text { tanpa } \\
\text { toleransi } & \end{array}$ & 4,56 & $\begin{array}{l}\text { Sangat } \\
\text { Setuju }\end{array}$ \\
\hline 5 & $\begin{array}{l}\text { Cara membayar dan } \\
\text { melunasi pajak sangat } \\
\text { mudah/efisien }\end{array}$ & 4,53 & $\begin{array}{l}\text { Sangat } \\
\text { Setuju }\end{array}$ \\
\hline & Total & 22,64 & \\
\hline & Nilai Rata-rata & 4,52 & $\begin{array}{l}\text { Sangat } \\
\text { Setuju }\end{array}$ \\
\hline
\end{tabular}

Sumber: Data diolah, 2017

\section{Pelayanan Fiskus}

Rekapitulasi skor tanggapan mengenai peelayanan fiskus terhadap kepatuuhan wajib pajk pada KPP Pratama Sukabumi pada tabel 10:

\begin{tabular}{|c|c|c|c|}
\hline No & $\begin{array}{c}\text { Pertanyaan/Pernyat } \\
\text { aan }\end{array}$ & $\begin{array}{c}\text { Jawab } \\
\text { an }\end{array}$ & $\begin{array}{c}\text { Keteran } \\
\text { gan }\end{array}$ \\
\hline 1 & $\begin{array}{ll}\text { Petugas pajak } & \text { telah } \\
\text { memberikan } & \\
\text { pelayanan } & \text { pajak } \\
\text { dengan baik } & \end{array}$ & 4,58 & $\begin{array}{l}\text { Sangat } \\
\text { Setuju }\end{array}$ \\
\hline 2 & $\begin{array}{l}\text { Petugas pajak } \\
\text { senantiasa } \\
\text { memperlakukan } \\
\text { Wajib Pajak secara } \\
\text { adil tanp pandang } \\
\text { bulu. }\end{array}$ & 4,43 & $\begin{array}{l}\text { Sangat } \\
\text { Setuju }\end{array}$ \\
\hline 3 & $\begin{array}{lr}\text { Penyuluhan yang } \\
\text { dilakkan oleh petugas } \\
\text { pajak dapat } \\
\text { membantu } \\
\begin{array}{l}\text { pemaahaman } \\
\text { mengenai hak dan } \\
\text { kewajibannya. }\end{array}\end{array}$ & 4,59 & $\begin{array}{l}\text { Sangat } \\
\text { Setuju }\end{array}$ \\
\hline 4 & $\begin{array}{l}\text { Petugas pjak senantia } \\
\text { memperhatikan } \\
\text { keberatan WP atas } \\
\text { pajak yang dikenakan }\end{array}$ & 4,59 & $\begin{array}{l}\text { Sangat } \\
\text { Setuju }\end{array}$ \\
\hline & Total & 18.19 & \\
\hline & Nilai Rata-rata & 4,54 & $\begin{array}{l}\text { Sangat } \\
\text { Setuju }\end{array}$ \\
\hline
\end{tabular}

Sumber: Data diolah, 2017 


\section{Kepatuhan Wajib Pajak}

Rekapitulasi skor tanggapan mengenai kepatuhan WP dilihat pada tabel 11:

Rekapitulasi Skor Tanggapan Variabel Kepatuhan Wajib Pajak

\begin{tabular}{|c|c|c|c|}
\hline No & $\begin{array}{l}\text { Pertanyaan/Pernyata } \\
\text { an }\end{array}$ & $\begin{array}{c}\text { Jawa } \\
\text { ban }\end{array}$ & Keterangan \\
\hline 1 & $\begin{array}{l}\text { Memahami Undang- } \\
\text { Undang perpajakan }\end{array}$ & 4,74 & $\begin{array}{l}\text { Sangat } \\
\text { Setuju }\end{array}$ \\
\hline 2 & $\begin{array}{l}\text { Mengisi formulir pajk } \\
\text { dengan benar }\end{array}$ & 4,67 & $\begin{array}{l}\text { Sangat } \\
\text { Setuju }\end{array}$ \\
\hline 3 & $\begin{array}{l}\text { Menyetor kembali } \\
\text { surat pemberitahuan } \\
\text { (SPT). }\end{array}$ & 4,61 & $\begin{array}{l}\text { Sangat } \\
\text { Setuju }\end{array}$ \\
\hline 4 & $\begin{array}{l}\text { Menghitung pajak } \\
\text { dengan jumlah pajak } \\
\text { yang benar }\end{array}$ & 4,51 & $\begin{array}{l}\text { Sangat } \\
\text { Setuju }\end{array}$ \\
\hline 5 & $\begin{array}{l}\text { Membayar pajak } \\
\text { tepat pada waktunya }\end{array}$ & 4,62 & $\begin{array}{l}\text { Sangat } \\
\text { Setuju }\end{array}$ \\
\hline & $\begin{array}{c}\text { Total } \\
\text { Nilai Rata-rata }\end{array}$ & $\begin{array}{c}23,15 \\
4,63\end{array}$ & $\begin{array}{l}\text { Sangat } \\
\text { Setuju }\end{array}$ \\
\hline
\end{tabular}

Sumber: Data diolah, 2017

\section{Pengujian Instrumen Uji Validitas}

Uji validitas dilakukan dengan menghitung korelasi antar masingmasing butir-butir pertanyaan dengan skor total pada masing-masing variabel, nilai tersebut dibandingkan dengan nilai rkritis.

Hasil uji validitas variabel Kesadaran WP $\left(\mathrm{X}_{1}\right)$, Sanksi Pajak $\left(\mathrm{X}_{2}\right)$, Pelayanan Fiskus $\left(\mathrm{X}_{3}\right)$, dan variabel Kepatuhan WP (Y) semua pertanyaan dinyatakan vaid karena $r_{\text {hitung }}$ masingmasing pertanyaan lebih besar dari rkritis. Sugiyono (2013) yang menjelaskan bahwa ketika nilai hitunf besarnya lebih dari atau sama dengan 0,3 maka data tersebut valid.

\section{Uji Reliabilitas}

Berdasarkan uji reliabilitas dari setiap rata-rata item pernyataan variabele ksadaran wajib pajak sebesar 0,814, sanksi pajak sebesar 0,819, pelayanan fiskus sebesar 0,811 dan kepatuhan wajb pajak sebesar 0,854, semua nilai tersebut menunjukan lebih besar dari 0,6 sehingga semua instrumen yang digunakan dapat dikatakan reliabel dan layak digunakan. Uji Normalitas

Hasil uji normalitas dengan metode one sample kolmogrov smirnov pada penelitin ini ditunjukan pada tabel 12:

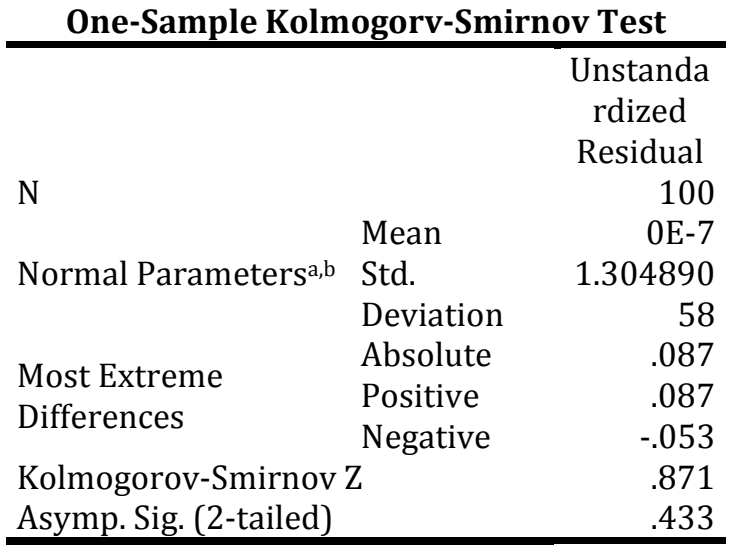

a. Test distributin is Normal.

b. Calculatd from data.

Sumber: Output data dengan SPSS 20, 2017

Terlihat bahwa hasil pengujian one sampel kolmogrov-smirnov nilai Asymp. Sig. (2-tailed) yaitu sebesar 0,433 , hal tersebut menunjukan bahwa bahwa data telah terdistribusi normsl karena Asyp. Sig. (2-tailed) lebih besar dari 0,05.

\section{Analisis Regresi Linier Berganda}

Analisis regresi diguanakan untuk mengetahui hubunga fungsional antara beberapa variabel bebas scara bersama-sama terhadap variabe terikat, dan juga untuk mengetahui jika nilai variabl independen dinaikan atau diturunkan nilainya, hasil analisis regresi linier berganda dilihat pada tabel 13: 
Coefficients $^{\mathrm{a}}$

\begin{tabular}{|c|c|c|c|c|c|}
\hline \multirow[t]{2}{*}{ Model } & \multicolumn{2}{|c|}{$\begin{array}{l}\text { Unstandardize } \\
\text { d Coefficients }\end{array}$} & $\begin{array}{c}\text { Standar } \\
\text { dized }\end{array}$ & \multirow[t]{2}{*}{$\mathrm{T}$} & \multirow[t]{2}{*}{ Sig. } \\
\hline & B & $\begin{array}{l}\text { Std. } \\
\text { Error }\end{array}$ & Beta & & \\
\hline $\begin{array}{l}\text { (Cons } \\
\operatorname{tant})\end{array}$ & -1.272 & 2.575 & & -.494 & .622 \\
\hline $\begin{array}{l}\text { kesad } \\
\text { aran } \\
\text { wajib }\end{array}$ & .444 & .081 & .479 & 5.521 & .000 \\
\hline 1 pajak & & & & & \\
\hline $\begin{array}{l}\text { sanksi } \\
\text { pajak }\end{array}$ & .305 & .094 & .276 & 3.250 & .002 \\
\hline $\begin{array}{l}\text { pelay } \\
\text { anan } \\
\text { fiskus }\end{array}$ & .384 & .138 & .190 & 2.780 & .007 \\
\hline
\end{tabular}

a. Depndent Variable: keptuhan wajib pajak.

Sumber: Output data SPSS 20, 2017

Berdasarkan tabel 13 diatas

diketahui bahwa nilai dari persamaan regeresi yaitu sebagai berikut:

$\mathrm{Y}=\mathrm{a}+\beta_{1} \mathrm{X}_{1}+\beta_{2} \mathrm{X}_{2}+\beta_{3} \mathrm{X}_{3}+$ ?

$Y=-1,272+0,444 \mathrm{X}_{1}+0,305 \mathrm{X}_{2}+0,384 \mathrm{X}_{3}+$ ?

Interpretasi dari regresi tersebut adalah sebagai beriku:

1. Nilai konstant sebesar -1,272, nilai tersebut mempunyai arti jika semua variabel bebas yaitu kesadaran wajib pajak (X1), sanksi pajak (X2), dan pelayanan fiskus (X3) dianggap tidak ada atau sama dengan 0 , maka skor kepatuhan wajib pajak akan semakin berkurag.

2. Variabel kesadaran wajib pajak (X1) sebesar 0,444. Hal tersebut menunjukan bahwa untuk setiap peningkatan kesadaran wajb pajk sebesar satu satuan, dengan asumsi variabek sanksi pajak dan pelayanan fiskus bernilai 0 , maka menyebabkan meningkatnya kepatuhan wajib pajak sebesar 0,444 .

3. Variabele sanksi pajak (X2) sebesar 0,305 . Menunjukan bahwa untuk setiap peningkatan sanksi pajak sebesar satu satuan, dengan asumsi variabel kesadaran WP dan pelayanaan fiskus bernilai 0 , maka menyebabkan meningkatnya kepatuhan wajib pajak sebesar 0,305.
Variabel pelayanan fiskus (X3) sebesar 0,384. Menunjukan bahwa untuk setiap peningkatan pelayanan fiskus sebesar satu satuan, dengan asumsi varibel kesadaran wajib pajak dan sanksi pajak bernilai 0, maka menyebabkan mningkatnya kepatuhan wajib pajak sebesar 0,384.

\section{Koefesien Korelasi Berganda}

Nilai koefesien korelasi pada tabel 14:

\section{Model Summary}

\begin{tabular}{|c|c|c|c|c|}
\hline Model & $.781^{\mathrm{a}}$ & R Square & $\begin{array}{l}\text { Adjust } \\
\text { ed R } \\
\text { Square } \\
598\end{array}$ & $\begin{array}{l}\text { Std. Eror } \\
\text { of the } \\
\text { Estimate } \\
1.325\end{array}$ \\
\hline $\begin{array}{l}\text { a. Predi } \\
\text { sanksi } \\
\text { b. Depe }\end{array}$ & $\begin{array}{l}\text { (Con } \\
\text { kesa } \\
\text { Vari }\end{array}$ & ble: kepa & $\begin{array}{l}\text { yanan fi } \\
\text { pajak } \\
\text { han waj }\end{array}$ & $\begin{array}{l}\text { kus, } \\
\text { pjak }\end{array}$ \\
\hline
\end{tabular}

Diperoleh nilai $\mathrm{R}$ sebesar 0,781, yang menunjukan berada pada interval nilai R (0,601-0,800) dengan derajat kekuatan hubungan yang kuat, sehingga terdapat pengarruh yang kuat antara variabel kesadaran wajiib pajk, sanksii pajak dan pelayanan fiskus terhadap kepatuhan WP,

\section{Koefesien Determinasi}

Hasil analisis koefesien determinasi dilihat pada tabel 15: Model Summary ${ }^{b}$

\begin{tabular}{|c|c|c|c|c|}
\hline $\begin{array}{l}\text { Mo } \\
\text { del }\end{array}$ & $\mathrm{R}$ & R Square & $\begin{array}{l}\text { Adjusted R } \\
\text { Square }\end{array}$ & $\begin{array}{l}\text { Std. Errorr } \\
\text { of the } \\
\text { Estimate }\end{array}$ \\
\hline 1 & $.781^{\mathrm{a}}$ & .610 & .598 & 1.325 \\
\hline
\end{tabular}

Diperoleh angka $\mathrm{R}^{2}$ ( $\mathrm{R}$ square) sebesar 0,610 atau (61\%). Hal iini meniunjukan bahwa kontribusi kesadaran wajib pajak, sanksi pajak dan pelayanan fiskus terhadap kepatuhan wajib pajak sebesar 61\%, sedangkan sisanya $39 \%$ dipengaruhi atau dijelaskan oleh variabel lain yang tidak dimasukan dalam model penelitian ini seperti ingkungan wajib pajak berada, pemahaman peraturan perpajakan dan tarif pajak. 


\section{Pengujian Hipotesis}

1. Uji F-test

Untuk mengeetahui pengaruh secara smultan (F-hitung) kesadaran wajib pajak, sanksi pajak dan pelayanan fiskus terhadap kepaatuhan wajib pajak di KPP Pratama Sukabumi, maka hipotesis yang digunakan sebagai berikut:

$H_{0}: \beta_{1}, \beta_{2}, \beta_{3}=0$; ksadaran wajib pajak, sanksi pajk dan pelaayanan fiskus tidak berpengaruh secara simultan terhadap kepatuhan wajib pajak.

$\mathrm{H}_{\mathrm{a}}: \beta_{1}, \beta_{2}, \beta_{3} \neq 0$; kesadarran wajiib pajak, sanksi pajak dan pelayanan fiskus berpengaruh secara simulltan terhadap kepatuhan wajib pajak.

Hasil uji $\mathrm{F}$ dapat diperoleh melalui tabel analisis analisis varians (Anova) pada tabel 15:

\begin{tabular}{|c|c|c|c|c|c|c|}
\hline \multirow{2}{*}{\multicolumn{2}{|c|}{ Model }} & \multicolumn{4}{|c|}{ ANOVA $^{\mathrm{a}}$} & \multirow[b]{2}{*}{ Sig. } \\
\hline & & Sum of & Df & Mean & $\mathrm{F}$ & \\
\hline \multirow{3}{*}{1} & $\begin{array}{l}\text { Regr } \\
\text { essio } \\
n\end{array}$ & 263.789 & 3 & 87.930 & 50.075 & $.000^{\mathrm{b}}$ \\
\hline & $\begin{array}{l}\text { Resi } \\
\text { dual }\end{array}$ & 168.571 & 96 & 1.756 & & \\
\hline & $\begin{array}{l}\text { Tota } \\
1\end{array}$ & 432.360 & 99 & & & \\
\hline
\end{tabular}

a. Dependent Variable: kpatuhan wajib pajak b. Predictors: (Constant), pelayanan fiskus, sanksi pajak, kesadaran wajib pajak

Sumber : Output data dengan SPSS 20, 2017

Dapat dilihat bahwa hasil pengujian uji $\mathrm{F}$, diperoleh nilai $\mathrm{F}_{\text {hitung }}$ sebesar 50,075, sedangkan $F_{\text {tabel }}$ sebesar 2,70. Maka $F_{\text {hitung }}>F_{\text {tabel }}(50,075>2,70)$ dengan nilai signifikansi $F$ sebesar 0,00 $<0,05$, berarti $\mathrm{H}_{0}$ ditolak dan $\mathrm{H}_{\mathrm{a}}$ diterima.

\section{Uji t-test}

Kriteria yang ditentukan dalam uji T ini yaitu jika thitung $>$ ttabel dari maka ditolak dan diterima, sedangkan jika $\leq$ maka diterima dan ditolak. Hipotesis yang digunakan yaitu sebagai berikut:

$\mathrm{H}_{\mathrm{o}}$ : $\beta_{1}=0$; kesadaraan wajib pajak tidak berpengaruh terhadap kepatuhan waajib pajak.
$\mathrm{H}_{\mathrm{a}}: \beta_{2} \neq 0$; sanksii pajak berpengaruh terhadap kepatuuhan wajib pajak.

$\mathrm{H}_{0}: \beta_{3}=0$; pelaayanan fiskus tidak berpengaruh terhadap kepatuhan wajib pajak

$\mathrm{H}_{\mathrm{a}}: \beta_{3} \neq 0$;pelayanan fiskus berpengaruh terhadp kepatuhan wajib pajak.

Hasil untuk uji t dapat dilihat pada tabel 16:

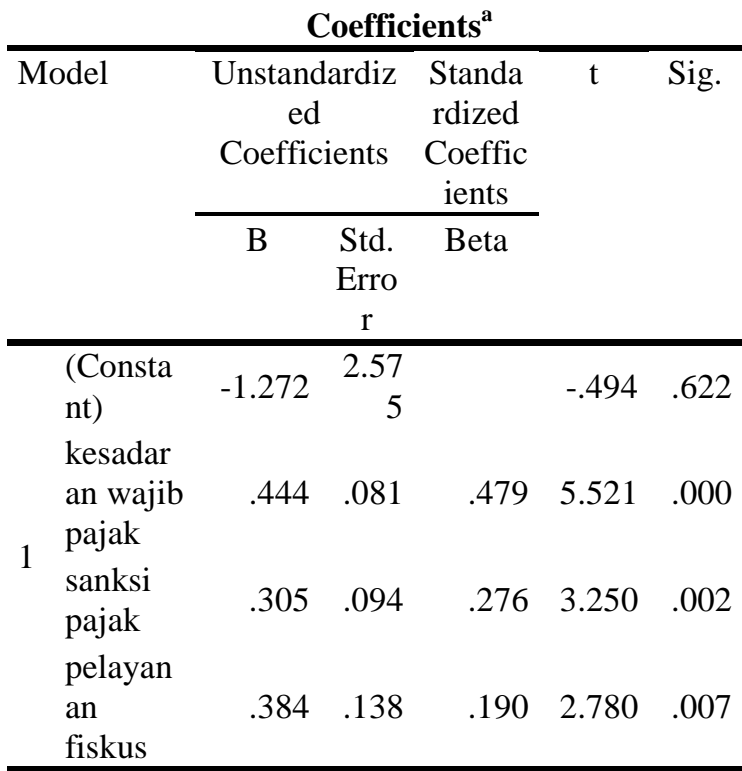

a. Depeendent Variable: kepatuhan wajib pajak Sumber : Output data dengan SPSS 20, 2017

Dapat dilihat uji $t$ untuk keesadaran wajib pajak sebesar 5,521, nilai $t_{\text {tabel }}$ sebesar 1,984 maka $t_{\text {hitung }}>$ $t_{\text {tabel }}(5,521>1,984)$ dengan tingkat signiifikan sebesar $0,00<0,05$, berarti $\mathrm{H}_{\mathrm{o}}$ dtolak dan $\mathrm{H}_{\mathrm{a}}$ diterima, maka kesadaaran wajiib pajak secara parsial berpengaruh terahadap kepatuhan wajib pajak di KPP Pratama Sukabumi.

Uji t untuk sanksi pajak diperoleh $t_{\text {hitung }}$ sebesar 3,250, sedangkan nilai $t_{\text {tabel }}$ sebesar 1,984 , maka $t_{\text {hitung }}>t_{\text {tabel }}(3,250$ $>1,984)$ dengan tingkat signifikan sebesar $0,002<0,05$, berarti Ho ditolak Ha diterima, maka sanksi pajak secara parsial berpengaruh terhadap kepatuhan wajib pajak di KPP Pratama Sukabumi.

Uji $\mathrm{t}$ untuk pelayanan fiskus diperoleh thitung sebesar 2,780, sedangkan nilai $t_{\text {tabel }}$ sebesar 1,984, maka $t_{\text {hitung }}>t_{\text {tabel }}(2,780>1,984)$ dengan tingkat signiifikan sebesar 0,007 
$<0,05$, berarti $\mathrm{H}_{\mathrm{o}}$ ditolak $\mathrm{H}_{\mathrm{a}}$ diterima, maka pelayannan fiskus scara parsial berpengaruh terhadap kepatuhan wajib pajak di KPP Pratama Sukabumi.

\section{Pembahasan \\ Deskripsi dan Karakteristik Responden}

Dalam penelitiian ini didominasi oleh laki-laki sebanyak 79 orang, dengan jenis wajib pajak badan sebanyak 62 responden, usia responden berkisar antara 36-40 tahun sebanyak 52 orang, dengan latar belakang pendidikan yaitu berasal dari S1, dpat disimpulkan bahwa karyawan perusahaan sebagian besar laki-laki dan yang wajiib menyeleenggarakan pembukuan adalah wajib pajak badan, usia disebabkan pengalaman hdup yang matang membuat mereka lebih paham dalam mengembangkan usaha dengan latar belakang pendidiikan S1.

\section{Uji F}

Berdasarrkan hasil uji $\mathrm{f}$ menunjukan bahwa kesadarran wajib pajak, sanksi pajak dan pelayannan fiskus berpengaruh positif terhadap kepatuhan wajib pajak, bila kesadaran wajib pajak baik otomatiis tingkat kepatuhan wajib pajak baik, begitu pula sanksi pajak diterapkan dengan baik dapat menyebabkan terpenuhinya kewajiban perpajakan olh wajib pajak sehingga dapat meniingkatkan kepatuhan wajib pajak itu sendiri, dan pelayanan fiskus bila kegiatan penyuluhan secara terus menerut kepada masyarakat agar mengetahui, mengakui, menghargai, dan menaati ketentuan pajak, diharapkan tujuan penerimaan pajak bisa berhasil dan otomatis tingkat kepatuhan akan bertambah.

Hasil penelitian ini mendukung penelitian yang dilaakukan oleh Tiraada (2013) dan Nugraheni dan Purwanto (2015) menyatakan bahwa keesadaran wajib pajak, sanksi pajak dan pelayanan fiskus berpengaruh positif signifikan secara simultan terhadap kepatuhan wajib pajak.

Uji t

\section{Pengaruh Kesadaran Wajib Pajak}

Adanya penngaruh yang signifiikan antra kesadaran wajib pajak dengan kepaatuhan wajib pajak disebabkan oleh variabel kesadaran wajib pajak yang melaporkan, membayar SPT tahunan. Dengan meningkatnya kepatuhan wajib pajak yang dilakukan oleh KPP Pratama Sukabumi akan berpengaruh terhadap kepatuhan wajib pajak dalam memenuhi kewajibannya dalam membayar pajak.

Hasil penelitian ini mendukung penelitian yang dilakukan oleh Arum (2012) bahwa kesadaran wajib pajak berpenngaruh positiif dan signifikan terhadap kepatuhan wajib pajak.

Pengaruh Sanksi Pajak

Adanya pengaruh sanksi pajak terahadap kepatuhan wajib pajak dikarenakan dengan diterapkannya sanksi sebagai akibat tidak terpenuhiinya kewajiban perpajakan oleh WP sebagaimana diamanatkan oleh UU perpajakan, pengenaan sanksi pajak pada wajib pajak akan menyebabkan terpenuhinya kewajibaan perpajakan oleeh wajib pajak sehingga daapat meningkattkan kepatuhan wajib pajak itu sendiri.

Hasil penelitian ini mendukung penelitiian yang dilakukan oleh Jatmiko (2006), Arum (2012), Rusli (2014), dan Tiraada (2013) bahwa sanksi pajak berpengaruh posiiitif dan signifikan terhadap kepatuhan wajib pajak.

\section{Pengaruh Pelayanan Fiskus}

Adanya pengaruh pelayanan fiskus terhadap kepatuhan wajib pajak dikarenakan dengan kegiatan yang dilakukan otoritas pajak dengan menyapa masyarakat agar menyampaikan SPT tepat waktu, 
termasuk penyulahan secara kontinyu melalui berbagai media, serta pegawai peduli NPWP dijalan, patut untuk dipuji, dengan penyulhan secara terus menerus kepada masyarakat agar mengetahui, mengakui, menghargai, dan mentaati ketentuan pajak, diharapkan tujuan penerimaan pajak bisa berhasil.

Hasil penelitian ini mendukung peneelitian yang dilakukan oleh Arum (2012), Jotopurnomo dan magoting (2013), dan Tiraada (2013) bahwa pelayaanan fiskus berpengaruh positif dan signifikan terhadap kepatuhan wajib pajak.

\section{Simpulan dan Saran}

\section{Simpulan}

1. Karakteristik responden dalam penelitian ini yaitu didominasi oleh laki-laki sebanyak 79 orang, dengan jenis wajib pajak badan sebanyak 62 responden, usia responden berkisar antara 36-40 tahun sebanyak 52 orang, dengan latar belakang pendidikan yaitu berasal dari S1.

2. Kesadaran wajib pajak, Sanki Pajak, dan Pelayanan Fiskus secara simultan berpengaruh terhadap Kepatuhan Wajib Pajak.

3. Kesadaran Wajib Pajak secara parsial berpengaruh terhadap Kepatuhan Wajib Pajak.

4. Sanksi Pajak secara parsial berpengaruh terhadap Kepatuhan Wajib Pajak.

5. Pelayanan Fiskus secara parsial berpengaruh terhadap Kepatuhan Wajib Pajak.

\section{Daftar Pustaka}

Arum, Harjanti Puspa, 2012, Pengaruh Kesadaaran Wajib Pajak, Pelayanan Fiskus, dan Sanksi Pajak terhadap Kepatuhan Wajib Pajak Orang Pribadi yang mlakukan Kegiataan Usaha dan Pekerjaan Bebas (Studi di Wilayah KPP Pratama

$\begin{array}{lr}\begin{array}{l}\text { Cilacap), Skripsi } \\ \text { dipublikasikan, }\end{array} & \begin{array}{r}\text { tidak } \\ \text { Fakultas }\end{array} \\ \text { Ekonomika dan } & \text { Bisnis, } \\ \text { Universitas Diponogoro. }\end{array}$

Direktorat Jendral Pajak. Surat Edaran Direktorat Jendral Nomor SE84/PJ/2011 tentang pelayanan prima.

Direktorat Jendral Pajak. Surat Edaran Direktorat Jendral Nomor SE06/PJ/2017 tentang straategi peningkatan kepatuhan wajib pajak \& penetapan target rasio kepatuhan wajib pajak tahun 2017.

Ghozali, Iman, 2011, Aplikasi Analisis Multivarlate dengan Program SPSS, Badan Penerbitan Universitas Diponogoro, Semarang.

Jatmiko, Agus Nugroho, 2006, Pengaruh Sikap WP Pada Pelaksaanaan Sanksi Denda, Pelayanan Fiskus Dan Kesadaran Perpajakan Terhadap Kepatuhan WP (Studi Empiris Terhadap Wajib Pajak Orang Pribadi Di Kota Semarang), Tesis Pascasarjana Universitas Diponogoro Semarang.

Nurmantu, Safri, 2005, Pengantar Perpajakan, Granit Jakarta.

Nugraheni, A.D, Purwanto, A, 2015 Faktor-Faktor yang Mempengaruhi Kepatuhan Wajib Pajak Oran Pribadi (Studi Empiris Pada Wajib Pajak Di Kota Magelang), Diponogoro Journal Of Accounting, Vol.4, No.3, tahun 2015, Hal 1-14.

Nugroho, Ahmad 2012, Faktor-Fakto yang Mempengaruhi Intelektual capital Disclousure, Accounting Analysis Journal. 1 (2). 
Ritongga, Pandapotan. 2011, Analisis

Pengaruh Kesadaran dan

Kepatuhan Wajib Pajak terhadap

Kinerja Kantor Pelayanan Pajak

(KPP) dengan Pelayanan Wajib

Pajak Orang Pribadi yang

Melakukan Kegiatan Usaha di

Kota Semarang), skripsi

Universitas Diponogoro, Semarang.

Sugiyono, 2007, Statstika untuk

Penelitian, Alfabeta, Bandung.

Tiraada, Tryaba A.M, 2013, Kesadaran

Perpajakan, Sanksi Pajak, Sikap

Fiskus terhadap Kepatuhan Wajib

Pajak Orang Pribadi di Kabupaten

Minahasa Selatan. Jurnal EMBA

Vol.1 No.3 Hal 999-1008. 